\title{
Application of Fuzzy Synthetic Evaluation for the Air Quality Assessment in the Selected Cities of China
}

\author{
Linan Yu, Haiyang He, Guoming Zhang \\ Airborne Survey and Remote Sensing Center of Nuclear Industry, Shi Jiazhuang, China \\ Email address: \\ yulnan21@163.com (Linan Yu), hhy8297@163.com (Haiyang He),guoming610@126.com (Guoming Zhang)
}

\section{To cite this article:}

Linan Yu, Haiyang He, Guoming Zhang. Application of Fuzzy Synthetic Evaluation for the Air Quality Assessment in the Selected Cities of China. International Journal of Environmental Protection and Policy. Vol. 6, No. 2, 2018, pp. 50-55. doi: 10.11648/j.ijepp.20180602.15

Received: April 19, 2018; Accepted: May 14, 2018; Published: June 21, 2018

\begin{abstract}
In this research, the air quality of six selected cities in China are evaluated according to the air monitoring data. Air pollutants including $\mathrm{SO}_{2}, \mathrm{NO}_{2}, \mathrm{PM}_{10}, \mathrm{PM}_{2.5}, \mathrm{CO}$ and $\mathrm{O}_{3}$ are chose as air quality indicators and compared with the ambient air quality standards of China (GB3095-2012). Using the fuzzy theory, the fuzzy synthetic evaluation model are constructed, and the air quality of the six selected cities are evaluated. Results show that the air quality of Beijing, Tianjing, Taiyuan, Dalian, Wuhan and Kunming in the year of 2014 belong to the second level in the ambient air quality standards of China (GB3095-2012). The air quality of the cities also obey the order: Kunming $>$ Dalian $>$ Taiyuan $>$ Beijing $>$ Wuhan $>$ Tianjing. It seems that $\mathrm{PM}_{2.5}$ and $\mathrm{PM}_{10}$ are the main pollutants in the atmosphere of the six selected cities. These results can help the environmental regulators to make the right policy in environmental management.
\end{abstract}

Keywords: Fuzzy Synthetic Evaluation, Air Quality Evaluation, Environmental Management

\section{Introduction}

With the rapid expansion of economy and increase of the number of vehicles and industries, environmental problems have become more and more serious [1]. Among them, air pollution is one of the serious environmental problems which may lead to acid rain, photochemical smog, greenhouse effect, ozone depletion. In addition, air pollution can further threaten human health and cause respiratory diseases, in which severe cases can be fatal. The main sources of air pollution are industrial combustion processes and automobile emissions. The Environmental Performance Index (EPI) shows that the air quality in China is the second worst among 180 countries included in the index this year (EPI (Environmental Performance Index, [2]). According to the 2013 Report on the State of Environment in China, although 74 cities in China adopted the new strict air quality standards in 2013, only three out of 74 cities' air quality met the national standard for good air quality [3]. However, China is not the only country that is faced with the air quality problem; many countries, especially developing countries, suffer from air pollution. In recent years, significant scientists and government have payed close attention to air pollution monitoring and air quality assessment in order to solve the issues [4]. Correct understanding and evaluation of the urban air quality, and development of a robust, accurate, yet simple, air quality assessment method are important for the controlling and prevention of air pollution which will be great significance for cities' development [5-8]. International organizations have spent great efforts on air pollutant assessment and monitoring such as the Environmental Protection Agency in United States (USEPA, [9]) and the Pan American Health Organization (PAHO, [10]). To improve the air quality, China government has established more than 2700 monitoring stations with more than 268,000 sets of monitoring instruments, and approximately 60,000 monitoring personnel (MEP Ministry of Environmental Protection, [11]).

The air environment is a very complicated system, and the degree of air pollution is a fuzzy concept, and therefore the evaluation standard should be a fuzzy problem. For air quality assessment, it is important to identify all types of possible scenarios and present different contaminant concentrations that can be harmful to health. Although the damage that each pollutant causes separately is known, it is hard to identify the degree of air pollution if all parameters have the different harmful possibilities. It is improper to evaluate the degree of air pollution by a digital indicator as a dividing line, and all 
aspects of the factors must be considered together [6]. Many efforts have been suggested for air quality evaluation using computational models such as fuzzy logic [12-15], artificial neural networks [16-17], associative memories [18], support vector machines [19], factor analysis [20], Bayesian models [21].

Recent works for air quality assessment based on fuzzy logic have been developed. By using the fuzzy theory, the uncertainty and ambiguity of various factors can be eliminated [7]. In air quality assessment, fuzzy logic based systems are useful due to subjectivity handling that allows interpreting any kind of knowledge, mapping it into several parallel evaluations. The main idea of fuzzy synthetic analysis is to provide good assessment using a reasoning process which will be influenced by a priority weighment. Thus it can provide an indicator more suited to reality. In Abdullah and Khalid [22], a fuzzy analysis is used for generating weights that are multiplied to different parameter indexes. Then, the air quality index is obtained by the sum of the particular results using an analytic hierarchy process. In this case, there is not an experimental analysis phase of this work. This work provides a good solution for evaluating atmosphere pollution.

For air quality assessment, different indices have been proposed to evaluate the air quality. The most original evaluation system is the "Pollutant Standard Index" (PSI), which is subsequently modified and replaced by the "Air Quality Index" (AQI). These two systems are developed and introduced by United States Environmental Protection Agency (US EPA, [23]). The PSI considers five air pollutants: sulfur dioxide $\left(\mathrm{SO}_{2}\right)$, nitrogen dioxide $\left(\mathrm{NO}_{2}\right)$, carbon monoxide $(\mathrm{CO})$, ozone $\left(\mathrm{O}_{3}\right)$, and particulate matter $\left(\mathrm{PM}_{10}\right)$. Compared to the PSI, $\mathrm{PM}_{2.5}$ and $8 \mathrm{-h}$ average ozone concentrations are added in the AQI [24]. The Ministry of Environmental Protection (MEP) of China promulgates new ambient air quality standards (GB3095-2012) in 2012, whereby $\mathrm{PM}_{2.5}$ and 8 -h average ozone concentrations are included and the concentration of pollutants in the limits are redefined.

The newly released technical regulations on air quality daily reports by China's MEP has been officially implemented in 2016 (http://kjs.mep.gov.cn/hjbhbz/bzwb/dqhjbh/jcgfffbz/201203/t 20120302_224166.htm). Compared with previous standard, the air pollution index (API) is replaced by the air quality index (AQI), and the daily concentrations of carbon monoxide $(\mathrm{CO})$ and fine particulate matter (aerodynamic diameter $\leqslant 2.5 \mu \mathrm{m} ; \mathrm{PM}_{2.5}$ ) as well as $1-\mathrm{hr}$ and $8-\mathrm{hr}$ maximum concentrations of $\mathrm{O}_{3}$ are added in the calculation. The $\mathrm{NO}_{2}$ limits are strengthened to 0.080 and $0.180 \mathrm{mg} \mathrm{m}^{-3}$ for an API of 50 and 100, respectively. According to the seven pollution factors pursued since March 2012, the number of days reaching the standard will be decreased by $10-30 \%$ by applying the new regulations. These changes will undoubtedly bring new challenges to the air pollution controls in Chinese cities [25].
In this research, the proposed fuzzy synthetic evaluation is applied of the selected cities in China to make the air quality assessment more scientifically. Six key pollutants have been studied in the selected cities: ozone (O3), sulphur dioxide $\left(\mathrm{SO}_{2}\right)$, nitrogen dioxide $\left(\mathrm{NO}_{2}\right)$, carbon monoxide $(\mathrm{CO})$, particulate matter smaller than 10 and $2.5 \mu \mathrm{m}\left(\mathrm{PM}_{10}\right.$ and $\mathrm{PM}_{2.5}$ ). The air quality assessment is based on the pollutant concentration levels, which can damage population health depending of the toxicity and exposure time [26]. In this case, the concentrations of six major air pollutants are used as the input to evaluate the air quality. The monitoring data are compared with the ambient air quality standards of China (GB3095-2012) [7]. Using the fuzzy theory, the fuzzy synthetic evaluation model are constructed in this study, and then an assessment on the air quality of the selected cities in China are made.

\section{Method}

In this section, methods applied in this paper are introduced briefly, including how to construct the fuzzy relation matrix and the way to calculate the weight of evaluation factors.

\subsection{Factor Set and Evaluation Set}

In this section, no computation is performed here, each node only transmits the inputs to the next layer. Factors constituting the environmental quality of the collection is:

$$
\mathrm{U}=\left\{\mathrm{u}_{1}, \mathrm{u}_{2}, \mathrm{u}_{3} \ldots, \mathrm{u}_{\mathrm{i}}\right\}
$$

Where $u_{1}, u_{2}, u_{3} \cdots, u_{i}$ mean the monitoring values from different kinds of environmental factors involved in the evaluation.

According to the ambient air quality standards of China (GB3095-2012), air quality must be based on the contaminants including: $\mathrm{SO}_{2}, \mathrm{NO}_{2}, \mathrm{PM}_{10}, \mathrm{PM}_{2.5}, \mathrm{CO}$ and $\mathrm{O}_{3}$. So the factor set can be described as:

$$
\mathrm{U}=\left\{\mathrm{SO}_{2}, \mathrm{NO}_{2}, \mathrm{PM}_{10}, \mathrm{PM}_{2.5}, \mathrm{CO}, \mathrm{O}_{3}\right\}
$$

Evaluation set is a collection of the evaluation outcomes, and they can be assessed by the evaluation outcomes. It can be described as:

$$
\mathrm{V}=\left\{\mathrm{v}_{1}, \mathrm{v}_{2}, \mathrm{v}_{3} \ldots, \mathrm{v}_{\mathrm{n}}\right\}
$$

Where $\mathrm{v}_{1}, \mathrm{v}_{2}, \mathrm{v}_{3} \cdots, \mathrm{v}_{\mathrm{n}}$ mean the different evaluation outcomes.

According to the ambient air quality standards of China (GB3095-2012) [27], air quality of China can be divided into two levels based on their negative effects on human health. Table 1 contains those classifications that have been considered by the GB3095-2012 and the concentration limits of indexes. And the factor set can be described as:

$$
\mathrm{V}=\{\mathrm{I}, \mathrm{II}\}
$$


Table 1. The concentration limits of pollutants in GB3095-2012 $\left(\mathrm{ug} / \mathrm{m}^{3}\right)$.

\begin{tabular}{llll}
\hline \multirow{2}{*}{ Pollutant } & Value Type & Concentration Limits & Level II \\
\cline { 3 - 4 } & Annual Average & Level I & 60 \\
$\mathrm{SO}_{2}$ & Annual Average & 20 & 40 \\
$\mathrm{NO}_{2}$ & Annual Average & 40 & 70 \\
$\mathrm{PM}_{10}$ & Annual Average & 40 & 35 \\
$\mathrm{PM}_{2.5}$ & 95th Percentile Daily Average & 15 & 4000 \\
$\mathrm{CO}$ & 90th Percentile Daily Maximum8 Hours Average & 4000 & 160 \\
$\mathrm{O}_{3}$ & & 100 & \\
\hline
\end{tabular}

\subsection{Membership Function and Fuzzy Relation Matrix}

Concentration levels of each pollutant and their allowed limits are important to be considered as input of the assessment model. In order to have a comprehensive understanding about air quality, considering each pollutant separately is important, calculating its concentration level according to a respective range that defines a negative effect in air pollution and the health of people. Therefore, it is important to determine the number of negative impacts that can be generated by a particular pollutant. An alternative solution of this problem is by using uncertainty to determine how much a concentration belongs to a determined condition; this value is calculated using a membership function.

The membership function is a parameter to describe the associate degree between pollutant content and its pollution level in the fuzzy synthetic evaluation. Membership functions transform input measurements of real-valued information into $[0,1]$ scores and they define the level that a concentration belongs to a specific range. There are no rules for building membership functions and they are built according to the problem context. Typical membership function are Gaussian, triangular and trapezoidal. Generally, trapezoidal and triangular functions are built for representing the level of the concentration to be assessed. For extremely high and good concentrations, trapezoidal functions are selected, using the minimal value when a pollutant is considered. Whereas the triangular function was selected when the center of the range can be considered as a neutral point in the intermedia levels [28].

In this paper, the membership function is taken as the down half trapezoidal distribution function [6]. When pollutants content are at Level I or II, the formula of membership function can be described as the following:

$$
\begin{gathered}
r_{i 1}=\left\{\begin{array}{c}
1, x_{i} \leq v_{i 1} \\
\frac{v_{i 2}-x_{i}}{v_{i 2}-v_{i 1}}, v_{i 1}<x_{i}<v_{i 2} \\
0, x_{i}>v_{i 2}
\end{array}\right. \\
r_{i 2}=\left\{\begin{array}{c}
0, x_{i} \leq v_{i 1} \\
\frac{x_{i}-v_{i 1}}{v_{i 2}-v_{i 1}}, v_{i 1}<x_{i}<v_{i 2} \\
1, x_{i} \geq v_{i 2}
\end{array}\right.
\end{gathered}
$$

Where $r_{i 1}$ and $r_{i 2}$ mean the membership value of factor $i$ at level I and level II, respectively; $x_{i}$ means the monitoring value of factor $i ; v_{i 1}$ and $v_{i 2}$ mean the limit concentration value of factor $i$ in level I and level II, respectively.
According to the air monitoring data and the limit concentration value, the membership value of different factors can be calculated through the formula (1) and (2). Once the membership values have been computed, the fuzzy relation matrix $\mathrm{R}$ can be described as the following:

$$
\mathrm{R}=r_{i j}=\left(\begin{array}{cccc}
r_{11} & r_{12} & \ldots & r_{1 n} \\
r_{21} & r_{22} & \ldots & r_{2 n} \\
\ldots & \ldots & \ldots & \ldots \\
r_{m 1} & r_{m 2} & \ldots & r_{m n}
\end{array}\right)
$$

\subsection{Weight Set of the Evaluation Factors}

The weight value of pollution factor is a measurement of the relative degree of the influence of pollutants on the air quality. Each pollution factor is assigned a different weight according to the influence of each factor. The weight set can be described as:

$$
\mathrm{W}=\left(\mathrm{w}_{1}, \mathrm{w}_{2}, \mathrm{w}_{3}, \ldots, \mathrm{w}_{\mathrm{n}}\right)
$$

The formula of weight value can be can be calculated as the following:

$$
w_{i}=\frac{\frac{x_{i}}{s_{i}}}{\sum_{j=1}^{n} \frac{x_{j}}{s_{j}}} ; i=1,2, \ldots, n
$$

Where $w_{i}$ and $x_{i}$ mean the weight value and monitoring value of factor $i ; s_{i}$ means the average value of limit concentrations in level I and II for factor $i$.

\subsection{The Fuzzy Synthetic Evaluation}

Once the standard values and monitoring values have been computed, the weight set (W) and the fuzzy relation matrix (R) can be calculated. Then the probability $(\mathrm{P})$ of the air quality at different levels can be computed. The formula is:

$$
p_{i}=\sum_{i=1}^{n} w_{i} r_{i j} ; i=1,2, \ldots, n
$$

Where $p_{i}$ is the probability value of the air quality at different levels. In accordance with the principle of maximum membership:

$$
\mathrm{P}=\max \left\{p_{1}, p_{2}, \ldots, p_{n}\right\}
$$

Subsequently, the max value represents the outcome of fuzzy synthetic evaluation of the air quality.

\section{Case Analysis}

In this research, the air quality of cities including Beijing, 
Tianjing, Taiyuan, Dalian, Wuhan, Kunming in China are evaluated. These cities are the most populated urban regions in China. Therefore, it is imperative for these six cities to scientifically assess air quality and accurately predict air pollutant concentration. The monitoring data of these cities come from the Statistical Yearbook of China in 2014 [29]. The concentrations of pollutants in the study areas are shown in Table 2.

From Table 2, several features of the air pollutants in these six selected cities can be summarized:

The values for the same air pollutants in the six cities all vary in the same range.

Taiyuan and Tianjin have the significantly higher $\mathrm{PM}_{10}$ and $\mathrm{PM}_{2.5}$ values than other cities.

Dalian and Kunming generally have lower pollutant concentrations than other cities.

According to the monitoring concentration of pollutants and the limit values, the fuzzy relation matrix of the selected cities can be calculated through the formula (1) and (2). And the results are shown in the Table 3.

The weight value of pollution factors is a measure of the impact of pollutants on ambient air quality, and directly affects the results of the comprehensive evaluation. The weight value of each pollutant can be calculated through the formula (3). The weights of six major air pollutants of the selected cities are presented in Table 4. Results show that $\mathrm{PM}_{2.5}$ and $\mathrm{PM}_{10}$ are the main pollutants in the ambient air of these six cities during the evaluation period. The weighting range for $\mathrm{PM}_{2.5}$ and $\mathrm{PM}_{10}$ are 0.26 0.36, andn0.21 0.25, respectively in these six cities, which are higher than other pollutants. The order of the subdominant pollutants is different in different cities. This result is consistent with previous researches through other assessment methods, suggesting that the most important pollutant in Chinese large cities is $\mathrm{PM}_{10}$ and $\mathrm{PM}_{10}[25,30]$.

The fuzzy relation matrix and weight values are combined together to obtain the fuzzy matrix, and the probability of the air quality in level I or II are assessed through formula (4). According to the principle of maximum membership, the maximum values of $\mathrm{p}_{1}, \mathrm{p}_{2}, \mathrm{p}_{3}, \mathrm{p}_{4}, \mathrm{p}_{5}$ and $\mathrm{p}_{6}$ are presented in Table 5. Results indicate that the air quality of Beijing, Tianjing, Taiyuan, Dalian, Wuhan and Kunming in 2014 should belong to the second level (level II) in the ambient air quality standards of China (GB3095-2012), and none of those cities has reached the level I. The air quality of the cities in the year of 2014 should obey the order: Kunming $>$ Dalian $>$ Taiyuan $>$ Beijing $>$ Wuhan $>$ Tianjing. The worst air quality city is Tianjing, which should be related with its large urban centers [25] and unexpectedly rapid growth in energy consumption. This should be the reason for the bad air quality in Wuhan and Beijing as well. Taiyuan is a traditional coal base of China with great number of coal mining industry, which should be related with the bad air quality. Dalian and Kunming shows better air quality than other cities, which should be attributed to the locations in the coastal and southwest areas of these two cities, respectively. The oceanic monsoon climate provide good diffusion condition of air pollutant, and decrease the pollutant concentrations in the ambient air. Coal has severe environmental implications compared to petroleum, natural gas, new and renewable energy sources [31]. The greater proportion of coal in the energy consumption has produced greater emissions of air pollutants. Structure adjustment of energy consumption should be taken for pollution emission reduction. Developing hydropower for ecological protection and resettlement in China should be considered, such as developing nuclear power, accelerating the development of natural gas and develop wind power, solar energy, biomass energy, and geothermal energy according to local conditions.

Table 4 also shows that annual $\mathrm{PM}_{10}$ concentrations in northern China (Beijing, Tianjing and Taiyuan) were higher than in the south (Kunming), while Wuhan city, which is located along the Yangtze River, also has high $\mathrm{PM}_{10}$ concentration. Generally, the pollution pattern of "more severe from south to north "in China. However, according to this result this pattern is becoming less obvious due to the decline of $\mathrm{PM}_{10}$ concentrations in the northern cities and the more obvious regional characteristics of air pollution. Emission control is one of the most important factors in urban pollution mitigation in northern China.

It has been proved that fuzzy synthetic evaluation method can be used to make an assessment on the air quality. On the other hand, it can even help the environmental regulators to make the right policy in environmental management.

Table 2. The monitoring concentration of pollutants from selected cities in $2014\left(\mathrm{ug} / \mathrm{m}^{3}\right)$.

\begin{tabular}{lllllll}
\hline \multirow{2}{*}{ City } & \multicolumn{7}{l}{ Pollutant Concentration } & & & \\
\cline { 2 - 7 } & $\mathbf{S O}_{\mathbf{2}}$ & $\mathbf{N O}_{\mathbf{2}}$ & $\mathbf{P M}_{\mathbf{1 0}}$ & $\mathbf{P M}_{\mathbf{2 . 5}}$ & $\mathbf{C O}$ & $\mathbf{O}_{\mathbf{3}}$ \\
\hline Beijing & 22 & 57 & 116 & 86 & 3200 & 200 \\
Tianjing & 49 & 54 & 133 & 83 & 2900 & 157 \\
Taiyuan & 73 & 36 & 138 & 72 & 3200 & 125 \\
Dalian & 30 & 39 & 85 & 53 & 1400 & 110 \\
Wuhan & 21 & 55 & 114 & 82 & 1800 & 156 \\
Kunming & 20 & 36 & 70 & 35 & 1500 & 111 \\
\hline
\end{tabular}

Table 3. The fuzzy relation matrix of the selected cities.

\begin{tabular}{|c|c|c|c|c|c|c|c|c|c|c|c|c|}
\hline \multirow{2}{*}{ Pollutant } & \multicolumn{2}{|c|}{ Beijing } & \multicolumn{2}{|c|}{ Tianjing } & \multicolumn{2}{|c|}{ Taiyuan } & \multicolumn{2}{|c|}{ Dalian } & \multicolumn{2}{|c|}{ Wuhan } & \multicolumn{2}{|c|}{ Kunming } \\
\hline & $r_{i 1}$ & $r_{i 2}$ & $r_{i 1}$ & $r_{i 2}$ & $r_{i 1}$ & $r_{i 2}$ & $r_{i 1}$ & $r_{i 2}$ & $r_{i 1}$ & $r_{i 2}$ & $r_{i 1}$ & $r_{i 2}$ \\
\hline $\mathrm{SO}_{2}$ & 0.95 & 0.05 & 0.275 & 0.725 & 0 & 1 & 0.75 & 0.25 & 0.975 & 0.025 & 1 & 0 \\
\hline $\mathrm{NO}_{2}$ & 0 & 1 & 0 & 1 & 1 & 0 & 1 & 0 & 0 & 1 & 1 & 0 \\
\hline $\mathrm{PM}_{10}$ & 0 & 1 & 0 & 1 & 0 & 1 & 0 & 1 & 0 & 1 & 0 & 1 \\
\hline $\mathrm{PM}_{2.5}$ & 0 & 1 & 0 & 1 & 0 & 1 & 0 & 1 & 0 & 1 & 0 & 1 \\
\hline $\mathrm{CO}$ & 1 & 0 & 1 & 0 & 1 & 0 & 1 & 0 & 1 & 0 & 1 & 0 \\
\hline $\mathrm{O}_{3}$ & 0 & 1 & 0.05 & 0.95 & 0.583 & 0.417 & 0.833 & 0.167 & 0.067 & 0.933 & 0.817 & 0.183 \\
\hline
\end{tabular}


Table 4. The pollutant weight values of the selected cities.

\begin{tabular}{lllllll}
\hline \multirow{2}{*}{ City } & \multicolumn{2}{l}{ Weight Value } & & & & CO \\
\cline { 2 - 7 } & $\mathbf{S O}_{\mathbf{2}}$ & $\mathbf{N O}_{\mathbf{2}}$ & $\mathbf{P M}_{\mathbf{1 0}}$ & $\mathbf{P M}_{\mathbf{2 . 5}}$ & $\mathbf{O}_{\mathbf{3}}$ & 0.156 \\
Beijing & 0.056 & 0.144 & 0.214 & 0.349 & 0.081 & 0.118 \\
Tianjing & 0.120 & 0.132 & 0.236 & 0.324 & 0.071 & 0.097 \\
Taiyuan & 0.185 & 0.091 & 0.254 & 0.292 & 0.081 & 0.128 \\
Dalian & 0.114 & 0.148 & 0.235 & 0.322 & 0.053 & 0.135 \\
Wuhan & 0.059 & 0.154 & 0.233 & 0.368 & 0.051 & 0.161 \\
Kunming & 0.094 & 0.170 & 0.240 & 0.264 & 0.071 & \\
\hline
\end{tabular}

Table 5. The probability of air quality in different standard level.

\begin{tabular}{lllllll}
\hline \multirow{2}{*}{ Standard Level } & Probability & & & & & \\
\cline { 2 - 7 } & Beijing & Tianjing & Taiyuan & Dalian & Wuhan & Kunming \\
\hline I & 0.134 & 0.109 & 0.229 & 0.393 & 0.118 & 0.467 \\
II & 0.866 & 0.891 & 0.771 & 0.607 & 0.882 & 0.533 \\
\hline
\end{tabular}

\section{Conclusion}

High levels of air pollution have significant influence on human health, animals, plants and the environment, which can cause respiratory diseases and physiological dysfunction. Therefore, it is urgent and important to establish an air quality monitoring and early warning system to evaluate the degree of air pollution scientifically, and forecast air pollutant concentrations more accurately. In this paper, fuzzy synthetic evaluation method was used to determine the main air pollutants and evaluate the level of air pollution. The evaluation results showed that the air quality of Beijing, Tianjing, Taiyuan, Dalian, Wuhan and Kunming in 2014 belong to the second level (level II) in the ambient air quality standards of China (GB3095-2012). The air quality of the cities in the year of 2014 obey the order: Kunming $>$ Dalian $>$ Taiyuan $>$ Beijing $>$ Wuhan $>$ Tianjing. $\mathrm{PM}_{2.5}$ and $\mathrm{PM}_{10}$ are the main pollutants in the atmosphere of the selected cities.

The prediction of air pollutant concentration is an important part of an air quality early warning system. Even though a national policy framework is in place, efforts are still required to develop measures for implementation of these policies in various regions with a consideration of local conditions.

\section{References}

[1] Yuan, X., Mu, R., Zuo, J., Wang, Q., 2015, Economic Development, Energy Consumption, and Air Pollution: A Critical Assessment in China, Human and Ecological Risk Assessment: An International Journal [J], 21:3, 781-798.

[2] EPI (Environmental Performance Index), 2016. Global Metrics for the Environment-The Environmental Performance Index Ranks Countries Performance on High-priority Environmental Issues [R].

(http://environment.yale.edu/news/article/2016-yaleenvironme ntal-performance-index-released/).

[3] Chinese Ministry of Environmental Protection (CMEP). Report on the State of Environment in China in 2013 [R], CMEP: Beijing, China, 2014. (In Chinese).

[4] Zhou X, Xu Y, Yuan S, et al. Performance and potential of solar updraft tower used as an effective measure to alleviate Chinese urban haze problem [J]. Renewable and Sustainable Energy Reviews, 2015, 51: 1499-1508.

[5] Wu Y X, Liu X. Application of Fuzzy Mathematical Comprehensive Evaluation for the Air Quality Evaluation in Dazhou [J]. Sichuan Environment, 2011, 30 (5): 63-66.

[6] Assessment and Analysis of Air Quality of Weinan from 2008 to 2014 [J]. Henan Science, 2015, 33 (10): 1838-1842.

[7] $\mathrm{Fu} \mathrm{H}$, Chen T. Application of fuzzy mathematical comprehensive evaluation of the atmosphere quality evaluation in Wuhan [J]. JOURNAL-HUBEI UNIVERSITY NATURAL SCIENCE EDITION, 2007, 29 (3): 298-301.

[8] Onkal-Engin G, Demir I, Hiz H. Assessment of urban air quality in Istanbul using fuzzy synthetic evaluation [J]. Atmospheric Environment, 2004, 38 (23): 3809-3815.

[9] USEPA United States Environmental Protection Agency, 2009. Technical Assistance Document for the Reporting of Daily Air Quality—The Air Quality Index (AQI) [R].

[10] PAHO Pan American Health Organization, 2015. Available at: http://www.paho.org (accessed August 2015) [Z].

[11] MEP (Ministry of Environmental Protection), 2015. Enhancing Capability to Support Decision - A Summary of Environmental Monitoring in the First Half of 2015[Z]. 〈http://www.mep.gov.cn/xxgk/hjyw/201508/t20150804_30768 2.shtml $\rangle$.

[12] Liu, K., Liang, H., Yeh, K., Chen, C., 2009. A qualitative decision support for environmental impact assessment using fuzzy logic [J]. Journal of Environmental Informatics. 13 (2), 93-103.

[13] Upadhyaya, G., Dashore, N., 2010. Monitoring of air pollution by using fuzzy logic [J]. International Journal on Computer Science \& Engineering. 02 (07), 2282-2286.

[14] Upadhyaya, G., Dashore, N., 2011. Fuzzy logic based model for monitoring air quality index [J]. Indian Journal of Science \& Technology. 4 (3), 15-218.

[15] Wang, B., Chen, Z., 2015. A model-based fuzzy set-OWA approach for integrated air pollution risk assessment [J]. Stochastic Environmental Research and Risk Assessment. 29 (5), 1413-1426. Mishra, D., Goyal, P., 2016. Neuro-fuzzy approach to forecast $\mathrm{NO}_{2}$ pollutants addressed to air quality dispersion model over Delhi, India [J]. Aerosol \& Air Quality Research. 16, 166-174. 
[16] Feng, Q., Wu, S., Du, Y., Xue, H., Xiao, F., Ban, X., Li, X., 2013. Improving neural network prediction accuracy for $\mathrm{PM}_{10}$ individual air quality index pollution levels $[\mathrm{J}]$. Environmental Engineering Science. 30 (12), 725-732.

[17] Mishra, D., Goyal, P., 2016. Neuro-fuzzy approach to forecast no2 pollutants addressed to air quality dispersion model over Delhi [J]. India Aerosol Air Quality Resource, 16, 166-174.

[18] Ruiz, J., Mayora, A., Torres, J., Ruiz, G., 1995. Short-term ozone forecasting by artificial neural networks [J]. Advances in Engineering Software. 23 (3), 143-149.

[19] Wang, W., Men, C., Lu, W., 2008. Online prediction model based on support vector machine [J]. Neurocomputing 71 (4-6), $550-558$.

[20] Bishoi, B., Prakash, A., Jain, V., 2009. A comparative study of air quality index based on factor analysis and USEPA methods for an urban environment [J]. Aerosol \& Air Quality Research. $9(1), 1-17$.

[21] Yong, L., Huaicheng, G., Guozhu, M., Pingjian, Y., 2008. A Bayesian hierarchical model for urban air quality prediction under uncertainty [J]. Atmospheric Environment, 42, 84648469 .

[22] Abdullah, L., Khalid, N. D., 2012. Classification of Air Quality Using Fuzzy Synthetic Multiplication [J]. Environmental Monitoring and Assessment, 184, 6957-6965.

[23] US EPA, 2009. Air Quality Index: A Guide to Air Quality and Your Health [R].
[24] Cheng, W., Chen, Y., Zhang, J., Lyons, T., Pai, J., Chang, S., 2007. Comparison of the revised air quality index with the PSI and AQI indices [J]. Sci. Total Environ. 382, 191-198.

[25] Wang L, Zhang P, Tan S, et al. Assessment of urban air quality in China using air pollution indices (APIs) [J]. Journal of the Air \& Waste Management Association, 2013, 63 (2):170.

[26] Wang, L., Jang, C., Zhang, Y., et al. Assessment of air quality benefits from national air pollution control policies in China. Part II: evaluation of air quality predictions and air quality benefits assessment [J]. Atmospheric Environment, 44 (2011): 3449-3457.

[27] Ministry of Environmental Protection of the People's Republic of China. The ambient air quality standards (GB3095-2012) [S]. Beijing: China Environmental Science Press, 2012.

[28] Olvera-García, M., Carbajal-Hernández, J., Sánchez-Fernández, L., et al. Air quality assessment using a weighted Fuzzy Inference System [J]. Ecological Informatics, 2016, 33:57-74.

[29] National Bureau of Statistics of the People's Republic of China. The Statistical Yearbook of China [M]. Beijing: China Environmental Science Press, 2014.

[30] Suppan P, Schrader S, Shen R, et al. Source apportionment and air quality impact assessment studies in Beijing, China [C], EGU General Assembly Conference. EGU General Assembly Conference Abstracts, 2012:12833.

[31] Liu, J., Diamond J., 2005. China's environment in a globalizing world [J]. Nature 435:1179-86. 